Electronic Supporting Information

\title{
Surface Properties and Protein Adsorption Performance of Fluorinated
}

\section{Amphiphilic Polymers}

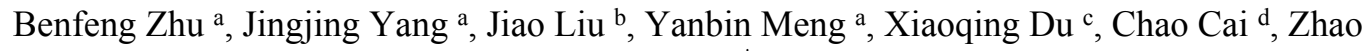
Zhang a,*

a Department of Chemistry, Zhejiang University, Hangzhou, Zhejiang, 310027, China

${ }^{\mathrm{b}}$ College of Chemistry and Chemical Engineering, Hunan University, Changsha, Hunan, 410082,

China

c School of Materials Science and Energy Engineering, Foshan University, Foshan, Guangdong, 528000, China

${ }^{\mathrm{d}}$ College of Chemical Engineering, Ningxia University, Yinchuan, Ningxia,750021, China

E-mail: zhaozhang@zju.edu.cn; Fax: +86-571-87951895; Tel: +86-571-87998538 


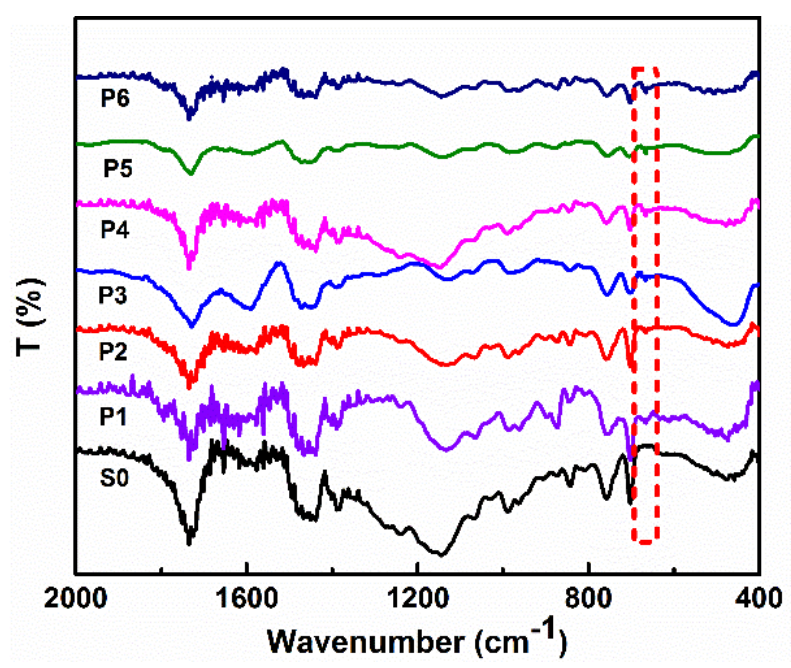

Figure S1. FT-IR spectra of S0 and P1-P6.

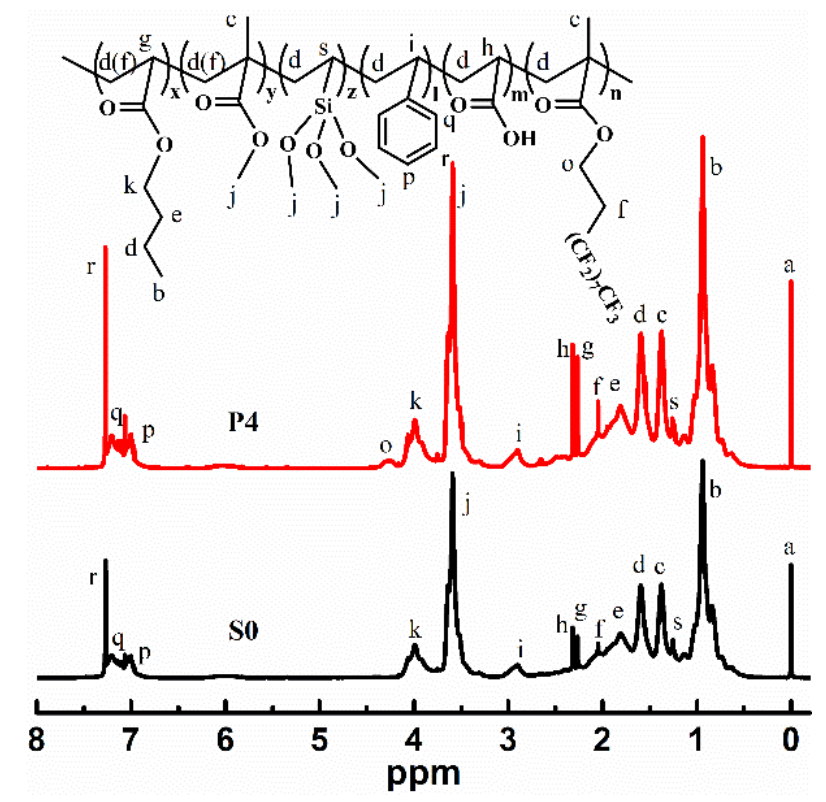

Figure S2. ${ }^{1} \mathrm{H}$ NMR spectra of S0 and P4. 

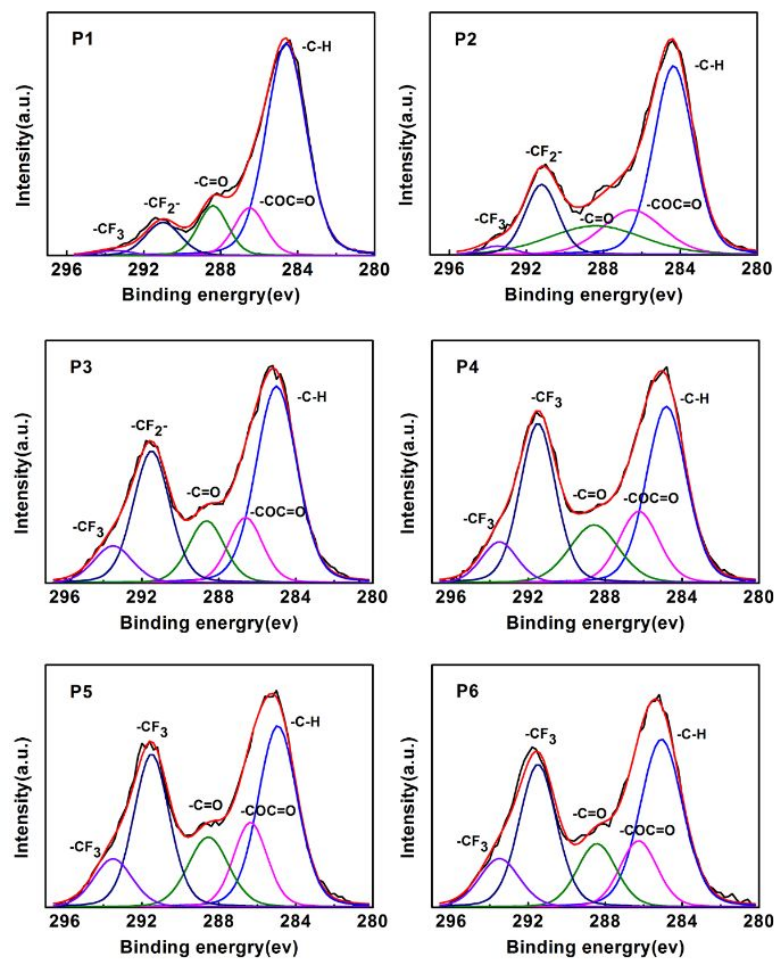

Figure S3. XPS $\mathrm{C}_{1 \mathrm{~s}}$ core level spectra of amphiphilic polymers with different number of FMA units; TOA $=30^{\circ}$.
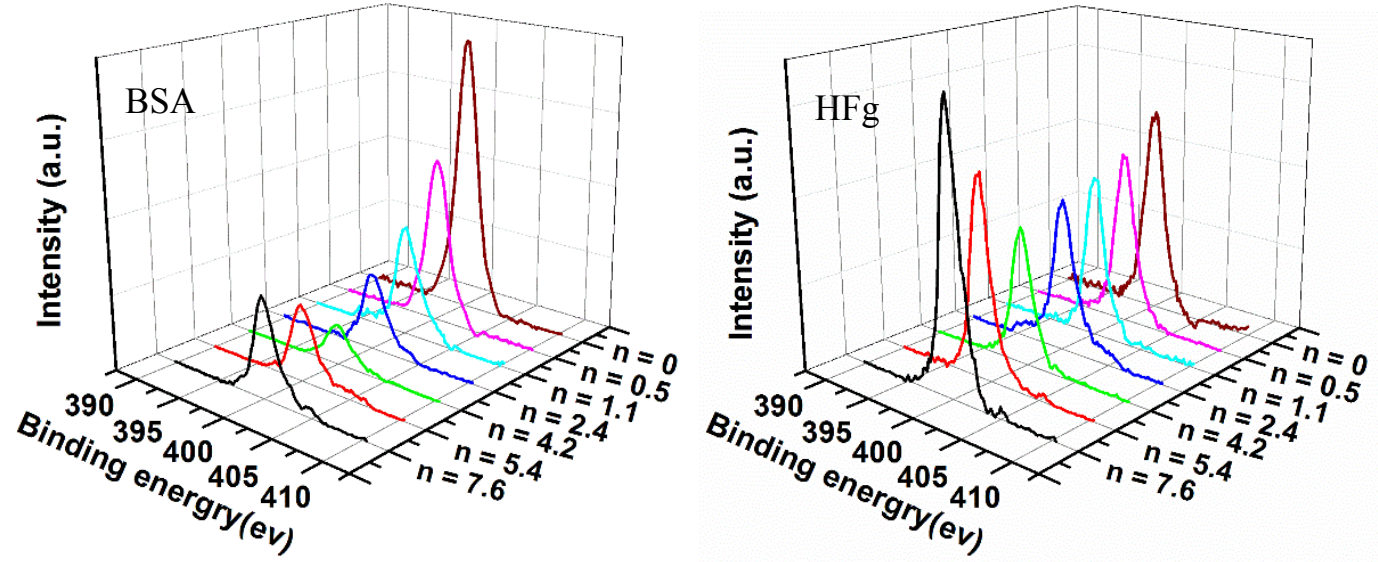

Figure S4. XPS spectra of $\mathrm{N}_{1 \mathrm{~s}}$ of polymers $\mathrm{S} 0$ and P1-P6 surface after proteins adsorbed. 


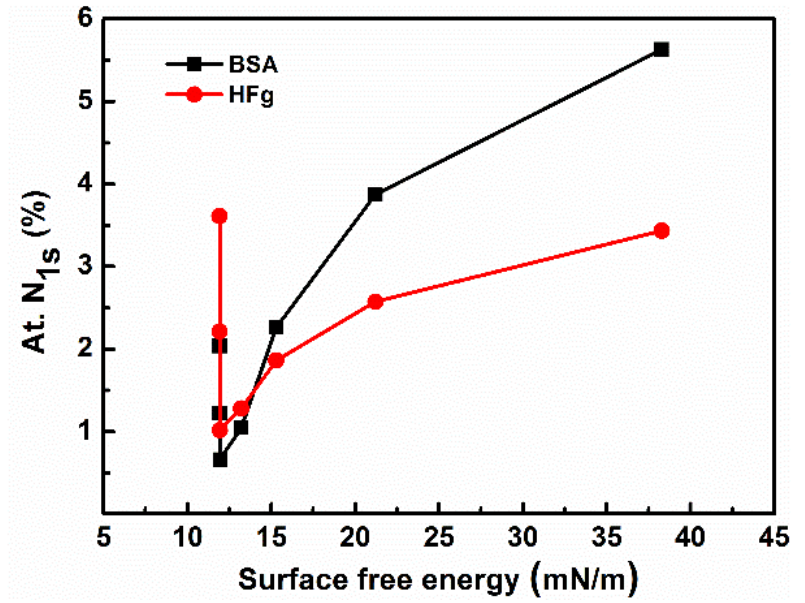

Figure S5. Plot of the atom percent of $\mathrm{N}_{1 \mathrm{~s}}$ versus surface free energy for samples surface.

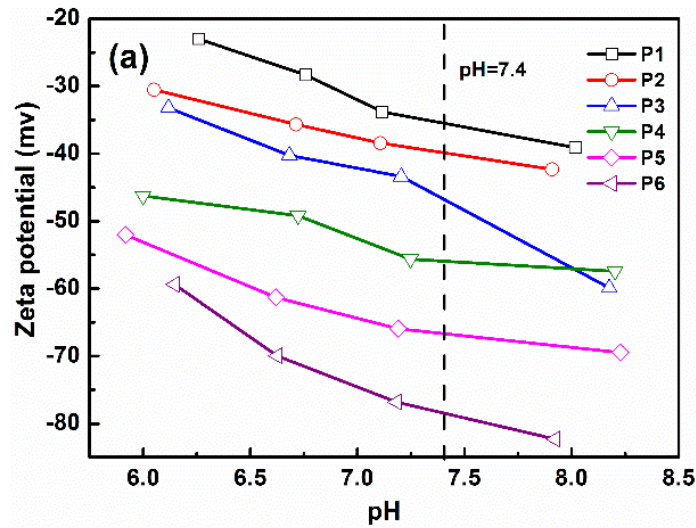

Figure S6. Zeta potentials of Pk films with different fluorine content. 